Article

\title{
Phenotypic Response of Wolbachia pipientis in a Cell-Free Medium
}

\author{
Alyssa M. Krafsur, Arnab Ghosh and Corey L. Brelsfoard * \\ Department of Biological Sciences, Texas Tech University, 2901 Main St., Lubbock, TX 79409, USA; \\ alyssa.krafsur@ttu.edu (A.M.K.); Arnab.Ghosh@ttu.edu (A.G.) \\ * Correspondence: Corey.Brelsfoard@ttu.edu
}

Received: 5 June 2020; Accepted: 14 July 2020; Published: 16 July 2020

\begin{abstract}
Wolbachia, an obligate intracellular bacterium estimated to infect millions of arthropod species worldwide, is currently being utilized in novel control strategies to limit the transmission of Dengue and Zika viruses. A limitation for Wolbachia-based control approaches is the difficulty of transferring Wolbachia to novel hosts and the lack of tools for the genetic transformation of Wolbachia due to the inability to culture Wolbachia outside the insect host cell in an axenic media. Here, we applied extracellular Wolbachia to phenotypic microarrays to measure the metabolic response of Wolbachia in media formulations with different $\mathrm{pH}$ levels and supplementation with Casamino acids. Results suggested a $\mathrm{pH}$ of $6.5-6.8$ and showed that the supplementation of $1 \mathrm{mg} / \mathrm{mL}$ casamino acids increased the survival and longevity of Wolbachia in an axenic medium. In addition, phenotypic microarrays are a useful tool to measure the phenotypic response of Wolbachia under different media conditions, as well as determine specific components that may be required for an axenic medium. This study is an initial step toward the development of a potential Wolbachia axenic culture system.
\end{abstract}

Keywords: axenic media; phenotypic microarray; Aa23; Wolbachia

\section{Introduction}

Wolbachia pipientis is an obligate intracellular maternally inherited bacterium found in $>55 \%$ of insects, as well as filarial nematodes and terrestrial crustaceans [1,2]. In insects, Wolbachia alters host reproduction with several phenotypes, including feminization, parthenogenesis, male killing, and cytoplasmic incompatibility (CI) [3]. The discovery of these reproductive alterations, particularly $\mathrm{CI}$, has caused Wolbachia to be a bacterium of interest for vector control. CI is used to drive desired phenotypes, such as refractoriness to disease transmission, with the goal of replacing natural infected populations [4-8]. In addition, Wolbachia-induced CI is also currently used as part of an incompatible insect technique (IIT) [9] strategy, where males harboring incompatible infections are released with the goal of suppressing natural populations by incompatible mating. An unexplored Wolbachia based approach centers around paratransgenesis, or the process of decreasing vector competence through genetically modifying an organism's symbionts. Due to the maternal transmission of Wolbachia and the reproductive advantage afforded by Wolbachia, it may be possible to use paratransgenesis to introduce a transgene into a population, in turn producing an antipathogenic molecule to block the transmission of vectored pathogens [8,10-12]. However, the genetic transformation of Wolbachia has not been achieved, due to the difficulty of delivering genetic constructs into an intracellular symbiont.

Through the observed horizontal transmission events, it is reasoned that Wolbachia must have spent a portion of their life cycle outside of their host. Empirical studies subsequently demonstrated Wolbachia can live outside of its host and retain viability for up to seven days [13]. Studies in vivo demonstrated the presence of Wolbachia in the hemolymph of both larvae and adults of Drosophila and mosquitoes, which provides further evidence for the idea that Wolbachia can survive extracellularly [14-17]. 
It would be beneficial from a research perspective for Wolbachia to replicate outside of the host cell, so the bacterium can be better studied and made easily available for transfection strategies. However, cellular replication has never been observed outside of its host cells, suggesting metabolic limitations or replication factors are not available or produced outside of the insect cells to support Wolbachia replication.

Wolbachia has a reduced genome similar to other intracellular symbionts and pathogens, which is consistent with the hypothesis that Wolbachia relies on its host cell machinery for energy sources and other metabolic factors [18-21]. Genomic studies have suggested the metabolic properties of Wolbachia are similar to Rickettsia bacteria, meaning Wolbachia may have limited carbohydrate metabolism, participate in lipid synthesis, and depend on amino acid transport [18-21]. Recent studies have also suggested that Wolbachia titers in host tissue are dependent upon ubiquitin and endoplasmic reticulum associated protein degradation pathways (ERAD) to supply sufficient amino acids for growth and reproduction [22]. The results of these studies also suggest the absence of glycolytic and gluconeogenic enzymes, the reduced pathways for amino acid biosynthesis, and the presence of transporters for proline, aspartate/glutamate, and alanine, which again suggests a reliance on host amino acids as a major energy source $[18,23]$.

The creation of a cell-free media to support intracellular endosymbiont growth has been accomplished before. Studies of the predicted metabolic capacities of bacteria from the genera Coxiella, Chlamydia, and Rickettsia and other obligate symbionts suggest a common nutritional deficiency of amino acids that is compensated for by the activities of amino acid and peptide permeates that scavenge amino acids from their hosts [24]. Particularly, the $Q$ fever bacterium Coxiella burnetii was systematically evaluated for conditions to support extracellular growth [25], leading to the development of a complex nutrient medium that supported replication and growth of the bacteria. Another factor to consider when constructing a cell-free media is the $\mathrm{pH}$ required for growth. The $\mathrm{pH}$ level for insect cell culture growth is well defined depending on the insect cell type, but intracellular $\mathrm{pH}$ levels can vary depending upon the media type and media $\mathrm{pH}$. Insect cell lines have been shown to have the highest growth rates and maximum densities at a $\mathrm{pH}$ of 6.2-6.8 [26]. In the presence of an acidic media, insect cells have been shown to have a capacity to buffer $\mathrm{pH}$ inside of cells and maintain a neutral $\mathrm{pH}$ level of 7.0 [27]. Previous attempts to isolate Wolbachia and examine replication were performed in Schneider's media at a pH of 6.2-6.5, which may be optimal for insect cells that can buffer the $\mathrm{pH}$ level, but not extracellular Wolbachia, which may require $\mathrm{pH}$ levels in an axenic media to be similar to intracellular levels of 6.5-7.0. Axenic growth of $C$. burnetii has fueled important new areas of research to aid in understanding disease transmission, as well as a new set of genetic tools for functional genetic studies of the pathogen [28-33]. Similar to C. burnetii, a Wolbachia axenic culture and associated toolset have the potential to open similarly broad vistas of research.

Besides what is predicted from genomic data, little knowledge of host factors and metabolic requirements for Wolbachia survival and replication is available. Using a similar approach as that which was successful for the development of other axenic intracellular bacteria cultures [34-39], we attempted to determine general host factors and metabolic requirements involved in Wolbachia survival outside of its host cell. Here, we used a phenotypic microarray approach to examine the response of Wolbachia in an axenic culture. Specifically, we altered the $\mathrm{pH}$ and casamino acid concentration in an axenic medium and measured the metabolic response of extracellular Wolbachia using phenotypic microarrays. Results will be useful for the future testing and identification of the conditions required for Wolbachia survival and extracellular growth in an axenic media.

\section{Materials and Methods}

\subsection{Cell Culture}

The $w$ AlbB infected Aa23 cell line used in experiments was obtained from Dr. Zhiyong Xi [40]. Cells were cultured in $25 \mathrm{~cm}^{2}$ or $75 \mathrm{~cm}^{2}$ cell culture flasks (Techno Plastic Products, Trasadingen, Switzerland) 
in Schneider's insect medium (SM) (MilliporeSigma, St. Louis, MO, USA) (Table S1) supplemented with $10 \%$ fetal bovine serum (FBS). All cell cultures were incubated at $28^{\circ} \mathrm{C}$ with a $\mathrm{CO}_{2}$ concentration of $\sim 0.2 \%$ (ambient atmospheric concentration). Cells were passaged at a 1:4 cell to media ratio every seven days. Aposymbiotic Aa23-T cells were generated by treating Aa23 cells with $3 \mathrm{mg} / \mathrm{mL}$ tetracycline for three passages, and subsequently referred to as Aa23-T.

\subsection{Trypan Blue Staining and Hemocytometer Aa23 Cell Counts}

To determine cell counts prior to Wolbachia isolations, $200 \mu \mathrm{L}$ of infected Aa23 cells were subjected to a centrifugation step at $200 \times g$ for $10 \mathrm{~min}$. The pellet was then resuspended in $200 \mu \mathrm{L}$ of $1 \times$ phosphate-buffered saline (PBS) solution. The cellular resuspension was then diluted in a 1:1 ratio with $0.4 \%$ Trypan Blue stain (Gibco, Carlsbad, CA, USA). Approximately $200 \mu \mathrm{L}$ of isolated Wolbachia was centrifuged for five minutes at $16,000 \times g$ and the pellet was also resuspended in $1 \times$ PBS solution and diluted with Trypan blue in an identical 1:1 ratio. After five minutes, $10 \mu \mathrm{L}$ of the two suspensions were placed in a hemocytometer and cells counted using a DMIL LED inverted microscope (Leica biosystems, Wetzlar, Germany) at 20× magnification. The hemocytometer grid images were captured using a 3 MP USB 2.0 Color CMOST Camera and software (v3.2.0000) (Amscope, Irvine, CA, USA).

\subsection{Confirmation of Wolbachia Infection Status Using PCR}

A DNeasy Blood and Tissue kit (Qiagen, Hilden, Germany) was used to extract DNA from cell lines and isolated extracellular Wolbachia following manufacturer's instructions. Wolbachia-specific primers were used to confirm the presence of Wolbachia in both intracellular and extracellular conditions [41-45]. Polymerase chain reaction (PCR) was also used to check for contamination of Acinetobacter spp., Cardinium spp., and Asaia spp. All primer sets to confirm Wolbachia infections and other bacterial contamination are listed in Supplementary Table S2. For all reactions, $1 \mu \mathrm{L}$ of isolated DNA was amplified in $25 \mathrm{mM}$ of KCL, $25 \mathrm{mM}$ of Tris-HCL (pH 9.0), $20 \mathrm{mM}$ of $\left(\mathrm{NH}_{4}\right)_{2} \mathrm{SO}_{4}$, and $0.025 \%$ Triton $\mathrm{X}-100,0.25 \mathrm{mM}$ of $\mathrm{MgCl}_{2}, 0.25 \mathrm{mM}$ of dNTPs, $0.5 \mathrm{mM}$ of primers, and $1 \mu \mathrm{L}$ of Taq DNA polymerase in a total volume of $25 \mu \mathrm{L}$. The PCR amplification protocol was $10 \mathrm{~min}$ at $95^{\circ} \mathrm{C}, 35$ cycles of $30 \mathrm{~s}$ at $95^{\circ} \mathrm{C}$, $30 \mathrm{~s}$ at $55^{\circ} \mathrm{C}$, and $1 \mathrm{~min}$ at $72{ }^{\circ} \mathrm{C}$, followed by a 10 -min extension step at $72{ }^{\circ} \mathrm{C}$. The PCR reaction was run on a T100 Thermocycler (Bio-Rad laboratories, Hercules, CA, USA). All reactions products were visualized on a 1.52-\% agarose gel, stained with GelRed (Biotium, Fremont, CA, USA), and visualized under ultraviolet illumination.

\subsection{Fluorescent In-Situ Hybridization}

Fluorescent in-situ hybridization (FISH) was performed on the Aa23 and Aa23-T cell lines to confirm the presence and absence of Wolbachia, respectively. Cells were grown to $90 \%$ confluency at $28^{\circ} \mathrm{C}$ and $300 \mu \mathrm{L}$ of the cells were added to four wells of an eight-well Nunc Lab-Tek ${ }^{\mathrm{TM}}$ Chamber slide system (ThermoFisher Scientific, Waltham, MA, USA). At 24 h post-extraction, isolated Wolbachia cells were added to the two of the other wells and Aa23-T cells were added to the two remaining wells. The cells were incubated in the chambered wells overnight for $15 \mathrm{~h}$ at $28^{\circ} \mathrm{C}$. Cells were taken out the next day and fixed in $4 \%$ formaldehyde (in $1 \times$ PBS) for $40 \mathrm{~min}$ at room temperature (RT). This was followed by two washes with $1 \times$ PBS. Next, the cells were prehybridized for $\sim 2 \mathrm{~h}$ at RT. The prehybridization buffer consisted of $50 \%$ deionized formamide, $20 \% 20 \times$ sodium saline citrate (SSC) solution, 1\% 50× Denhardt's Reagent, $10 \% 1 \mathrm{~mol}$ of dithriothreitol (DTT), $0.25 \mathrm{of} \mathrm{mg} / \mathrm{mL} \mathrm{t}-\mathrm{RNA}$, and $0.25 \mathrm{mg} / \mathrm{mL}$ of poly(A). The prehybridization step was followed with overnight hybridization $(\sim 18 \mathrm{~h})$ at $37{ }^{\circ} \mathrm{C}$ with gentle shaking. The prehybridization buffer was supplemented with $200 \mathrm{mg} / \mathrm{mL}$ of dextran sulfate, $250 \mathrm{mg} / \mathrm{liter}$ of salmon sperm DNA, and Wolbachia-specific probes (5'-/56-FAM/AATCCGGCCGARCCGACCC-3'); 5'-/56-FAM/CTTCTGTGAGTACCGTCATTATC-3') [13]. After hybridization, the cells were washed with denatured SSC solution in the following order: Wash buffer 1 (1× SSC augmented with 10 $\mathrm{mmol} /$ liter DTT) at RT with gentle shaking, wash buffer 1 at $55^{\circ} \mathrm{C}$ with gentle shaking, and two washes at $55^{\circ} \mathrm{C}$ with buffer $2(0.5 \times$ SSC augmented with $10 \mathrm{mmol} /$ liter DTT) with gentle shaking. Following the 
wash steps, cells were stained with DAPI at room temperature for $5 \mathrm{~min}$ followed by three washes with $1 \times$ PBS for 5 min each. The cells were then observed under a BX-41 epifluorescence microscope (Nikon, Tokyo, Japan) with appropriate filters at 60x magnification. Images were captured and processed with the help of QCapture ${ }^{\mathrm{TM}}$ software (v2.0.12) (Teledyne Qimaging, Surry, British Columbia, Canada).

\subsection{Isolation of Extracellular Wolbachia}

To isolate the $w$ AlbB infection, a mean of $9.59 \times 10^{5} \pm 1.97 \times 10^{4}$ cells was normalized during the log growth phase and used for each isolation procedure (Figure 1a). Extracellular Wolbachia was isolated using a modified procedure previously described [13]. Before the final centrifugation step, $200 \mu \mathrm{L}$ of a $250-\mathrm{mM}$ sucrose solution was added to each milliliter of isolated Wolbachia solution. The final centrifugation step was performed at $17,000 \times g$ for $10 \mathrm{~min}$. The resulting pellet contained extracellular Wolbachia and after discarding the supernatant, the pellet was resuspended in SM $+10 \%$ fetal bovine solution (FBS) and passed through a $2.7-\mu \mathrm{M}$ filter. To examine for potential environmental contamination, $20 \mu \mathrm{L}$ of the isolation solution was streaked on LB agar and incubated for $48 \mathrm{~h}$ at $28^{\circ} \mathrm{C}$.
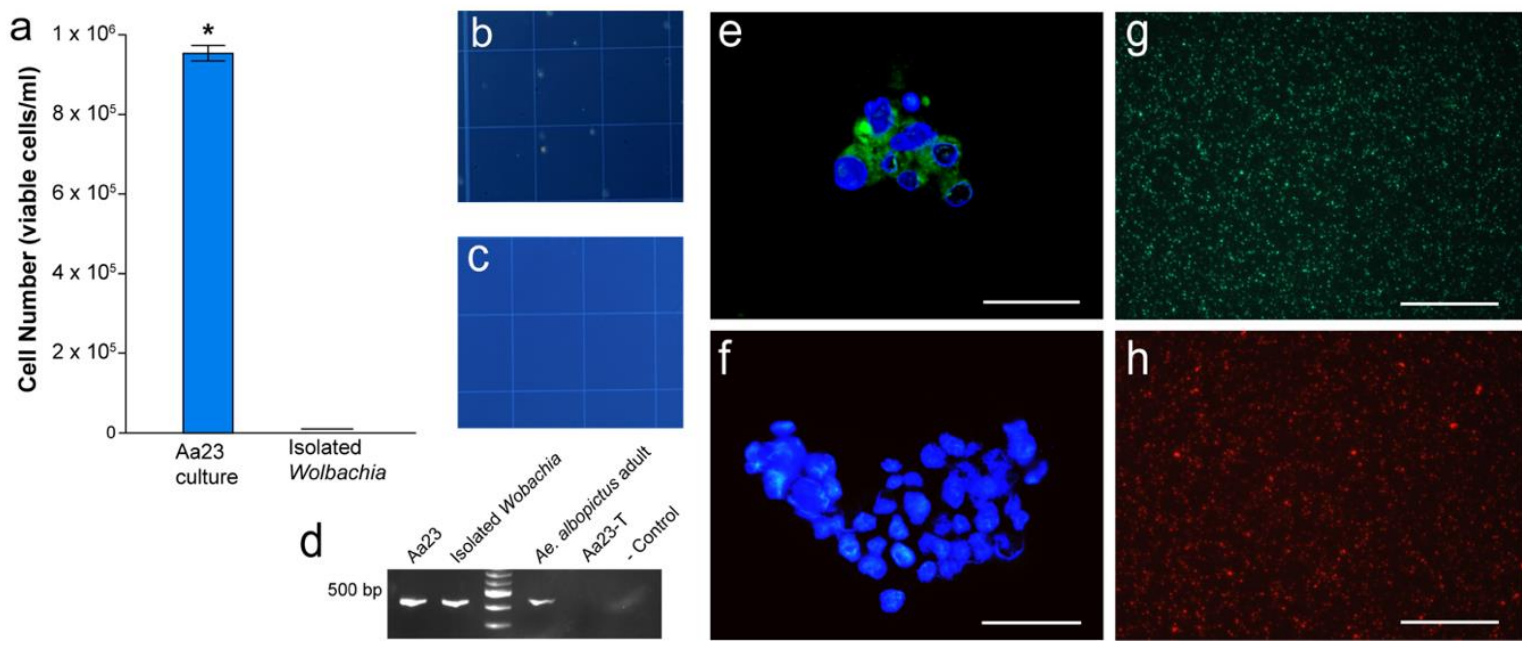

Figure 1. (a) Aa23 cell counts prior to Wolbachia isolation procedures. * above the bars represents a significant difference (t-test, $p<0.05)$, (b) pre- and (c) post-Wolbachia isolation using Trypan Blue stain, (d) Polymerase chain reaction (PCR) confirmation of Wolbachia infections in Aa23 cells and isolations, (e) Fluorescent in-situ hybridization (FISH) staining of Aa23 cells confirming Wolbachia infection, (f) FISH staining of Aa23-T aposymbiotic cells showing the absence of a Wolbachia infection, and (g) Baclight LIVE/DEAD ${ }^{\mathrm{TM}}$ staining of Wolbachia immediately after isolation procedures, and (h) Baclight LIVE/DEAD ${ }^{\mathrm{TM}}$ staining of heat killed Wolbachia. White scale bars represent $50 \mu \mathrm{M}$.

\subsection{Epifluorescence Microscopy}

To confirm the isolation of extracellular Wolbachia, a Baclight LIVE/DEAD ${ }^{\mathrm{TM}}$ bacterial viability kit was used to visualize the bacterium (ThermoFisher Scientific, Waltham, MA, USA). SYTO9 and propidium iodide (PI) were used to differentiate the live and dead bacterial cells following manufacturer's instructions. Briefly, $100 \mu \mathrm{L}$ of each of SYTO9 and PI were pre-mixed to prepare the stain mix and $10 \mu \mathrm{L}$ of the extracellular Wolbachia was added to the stain mix in a 1:1 ratio. This mixture was incubated in the dark for $10 \mathrm{~min}$. The bacteria-stain mix $(20 \mu \mathrm{L})$ was then placed on a glass slide, covered with a coverslip, and viewed using a Nikon BX41 inverted microscope at 100× magnification. To confirm staining efficacy, extracellular Wolbachia were heat-killed at $95{ }^{\circ} \mathrm{C}$ for $15 \mathrm{~min}$ and subsequently stained. Images were processed with QCapture ${ }^{\mathrm{TM}}$ software (v2.0.12) (Teledyne Qimaging, Surry, British Columbia, Canada). 


\subsection{Phenotypic Microarray Assays}

Two categories of phenotypic microarray (PM) plates, PM1 carbon source plates and PM3B nitrogen source plates (Biolog, Hayward, CA, USA), were used to assess the metabolic activity of extracellular Wolbachia [46]. Biological replicates of each plate type and treatment were completed in duplicate or triplicate. For treatment plates, $100 \mu \mathrm{L}$ of isolated Wolbachia in post-isolation media (SM supplemented with 10\% FBS with either an adjusted $\mathrm{pH}$ or the addition of casamino acids) was added to each well with $110 \mu \mathrm{L}$ of Redox Mix G (Biolog, Hayward, CA, USA). Control plates for the normalization of background absorbance consisted of post-isolation media at a $\mathrm{pH}$ of 6.8 for both PM1 and PM3B microarray plate assays. PM1 and PM3B microarray plates were incubated at $28{ }^{\circ} \mathrm{C}$ with a $\mathrm{CO}_{2}$ concentration of $\sim 0.2 \%$ for four days. To examine for an effect of $\mathrm{pH}$ on the survival of the extracellular Wolbachia in an axenic medium, the unbuffered $\mathrm{pH}$ of the post-isolation media ( 6.8) was adjusted to 6.5, 7, and 7.5, respectively. The resulting media was filter sterilized using a $0.2-\mu \mathrm{m}$ filter before being used for the isolation of Wolbachia. To examine for an effect of casamino acids on extracellular Wolbachia, the post-isolation media was supplemented with $1 \mathrm{mg} / \mathrm{mL}$, $2 \mathrm{mg} / \mathrm{mL}$, and $4 \mathrm{mg} / \mathrm{mL}$ of casamino acids (VWR chemicals, Solon, $\mathrm{OH}, \mathrm{USA}$ ) and filter sterilized. The absorbance measured for each well on the PM plates was at an O.D. of 600 in a Biotek Synergy H1 Microplate Reader (Biotek, Winooski, VT, USA). Absorbance measurements were analyzed using a Biotek Gen 5 Microplate Reader and imager software v.3.02 (Biotek, Winooski, VT, USA). All absorbance measurements were taken every $24 \mathrm{~h}$ over a period of four days. To normalize absorbance values and to account for background noise from the isolation medium, absorbance values from control plates were subtracted from the treatment plate absorbance values for each plate type and replicate.

\subsection{Quantitative Real-Time PCR Analysis}

Extracellular Wolbachia was quantified using quantitative polymerase chain reaction (qPCR). DNA was isolated using a Qiagen DNeasy kit (Qiagen, Hilden, Germany) following the manufacturer's instructions. qPCR was performed using PowerUp ${ }^{\mathrm{TM}}$ SYBR ${ }^{\mathrm{TM}}$ Green Master Mix (Applied Biosystems, Foster City, CA, USA) following manufacturer instructions with an ABI 7300 real-time qPCR system (Applied Biosystems, Foster City, CA, USA). Primers used for reactions are listed in Table S2. Wolbachia absolute cell counts were quantified by performing a serial dilution of an Aa23 cell culture sample and the generation of a standard curve. Three biological replicate samples were amplified in triplicate and the average $C_{t}$ values were used to quantify Wolbachia.

\subsection{Wolbachia Cell Counts}

To confirm the isolation of extracellular Wolbachia a Baclight LIVE/DEAD ${ }^{\mathrm{TM}}$ bacterial viability kit (ThermoFisher Scientific, Waltham, MA, USA) was used to differentiate live and dead bacterial cells following manufacturer's instructions. Ten $\mu \mathrm{L}$ of the stained solution was placed on a slide with a cover slip and imaged at 100x using a Nikon BX41 inverted microscope with epifluorescence. Viable Wolbachia cells stained green (SYTO9) and dead cells stained red (PI). Viable cells were counted using three representative images using Image-J.

\subsection{Statistical Analyses}

All statistical analyses were performed using JMP software (SAS, Cary, NC, USA). Statistical difference of Wolbachia counts using qPCR at each timepoint were determined using t-tests, with a significance level of $p<0.05$. Heatmaps were generated using mean absorbance values from replicate phenotypic microarray assays. All data from phenotypic microarrays for the different treatment levels of casamino acids and $\mathrm{pH}$ were combined into a single data matrix. Differences between phenotypic microarray treatment groups within each time point were determined using a one-way analysis of variance (ANOVA). Differences in cell counts were determined using Kruskall-Wallis and pairwise 
Mann-Whitney tests. Difference between treatment levels were considered to be significant when the $p$-value was $<0.05$.

\section{Results}

\subsection{Confirmation of Wolbachia Infections and Isolation of Wolbachia}

To determine that only Wolbachia was in the isolate and there were no residual cells, Aa23 cells isolates were stained with trypan blue. An analysis of the ratio of white (living) to blue (dead) Aa23 cells from three independent observations showed no Aa23 cells were observed in the Wolbachia isolate (Figure 1b,c). Wolbachia infections were confirmed in Aa23 cells and isolates using PCR and FISH (Figure 1d-f). Live Wolbachia was observed immediately after isolation using an SYTO9 stain as shown by green cells (Figure 1g). In addition, a heat-killed isolated Wolbachia sample showed only PI red-stained cells (Figure 1h). Aedes albopictus is known to harbor other bacterial symbionts, including Cardinium spp., Asaia spp., and Acinetobacter spp. [42,47], which could confound metabolic assays. Results from PCR assays suggest that isolates contained no Asaia spp., Cardinium spp., or Acinetobacter DNA (Table S3). Streaking of the Wolbachia isolate on LB plates also showed no evidence of contamination resulting from the isolation procedure. Plates remained colony-free after the 48 -h incubation period.

\subsection{Phenotypic Microarray Assays}

Phenotypic microarrays (PM) were used to measure the metabolic response of axenic Wolbachia to changes in $\mathrm{pH}$ over a four-day period. The range of normalized absorbance values $(\mathrm{Au})$ of PM1 microarray plates were: $\mathrm{pH}$ 6.5-0.072-2.429, 6.8-0.073-1.32; 7.0-0.076-1.785; 7.5-0.065-1.779; Casamino acids $0 \mathrm{mg} / \mathrm{mL}-0.056-1.163,1 \mathrm{mg} / \mathrm{mL}-0.061-1.221,2 \mathrm{mg} / \mathrm{mL}-0.058-1.17$, $4 \mathrm{mg} / \mathrm{mL}-0.054-1.992$. The range of normalized absorbance values of PM3 microarray plates were: $\mathrm{pH}$ 6.5-0.051-0.451, 6.8-0.052-1.005, 7.0-0.05-1.402, 7.5-0.051-0.885; Casamino acids $0 \mathrm{mg} / \mathrm{mL}-0.048-0.889,1 \mathrm{mg} / \mathrm{mL}-0.05-1.477,2 \mathrm{mg} / \mathrm{mL}-0.049-0.861,4 \mathrm{mg} / \mathrm{mL}-0.051-1.168$. Changes to media $\mathrm{pH}$ were demonstrated to impact the metabolic response of Wolbachia when added to PM1 plates (ANOVA, Day 1, F = 7.58, $p<0.0001$; Day 2, F = 30.9, F < 0.0001; Day 3, F = 3.0, $p=0.0293$; Day $4, \mathrm{~F}=2.8, p=0.0343)$. Media formulations of a $\mathrm{pH}$ of 6.5 and 6.8 typically had the highest metabolic response when examining absorbance values compared to media $\mathrm{pH}$ values of 7.0, and 7.5 (Figure 2). However, little differences in absorbance values were observed between the media formulations of different $\mathrm{pH}$ values when using PM3B plates (ANOVA, Day 1, F = 2.40, $p=0.0663$; Day 2, F = 1.26, $p=0.2855 ;$ Day 3, $\mathrm{F}=1.93, p=0.1217$; Day 4, F = 5.2135, $p=0.0014$ ) (Figure 3). The metabolic response of axenic Wolbachia was also measured in response to changes in casamino acid concentrations in post-isolation media. Changes to media casamino acid concentration was demonstrated to impact the metabolic response of Wolbachia on PM1 plates (ANOVA, Day 1, F = 25.75, $p<0.0001$; Day 2, F = 18.71, $p=<0.0001$; Day 3, $\mathrm{F}=7.05, p=0.0001$; Day $4, \mathrm{~F}=5.10, p=0.0016$ ). When examining absorbance values, media formulations with a casamino acid concentration of $1 \mathrm{mg} / \mathrm{mL}$ had the highest metabolic response as compared to media formulations with no supplemented casamino acids, $2 \mathrm{mg} / \mathrm{mL}$, and $4 \mathrm{mg} / \mathrm{mL}$ on PM1 plates (Figure 4). No difference in absorbance values were observed in media formulations with different casamino acid concentrations on PM3 plates (ANOVA, Day 1, F = 1.23, $p=0.30$; Day 2, $\mathrm{F}=2.39, p=0.07$; Day 3, $\mathrm{F}=1.23, p=0.30$; Day $4, \mathrm{~F}=0.66, p=0.57$ ) (Figure 5). 


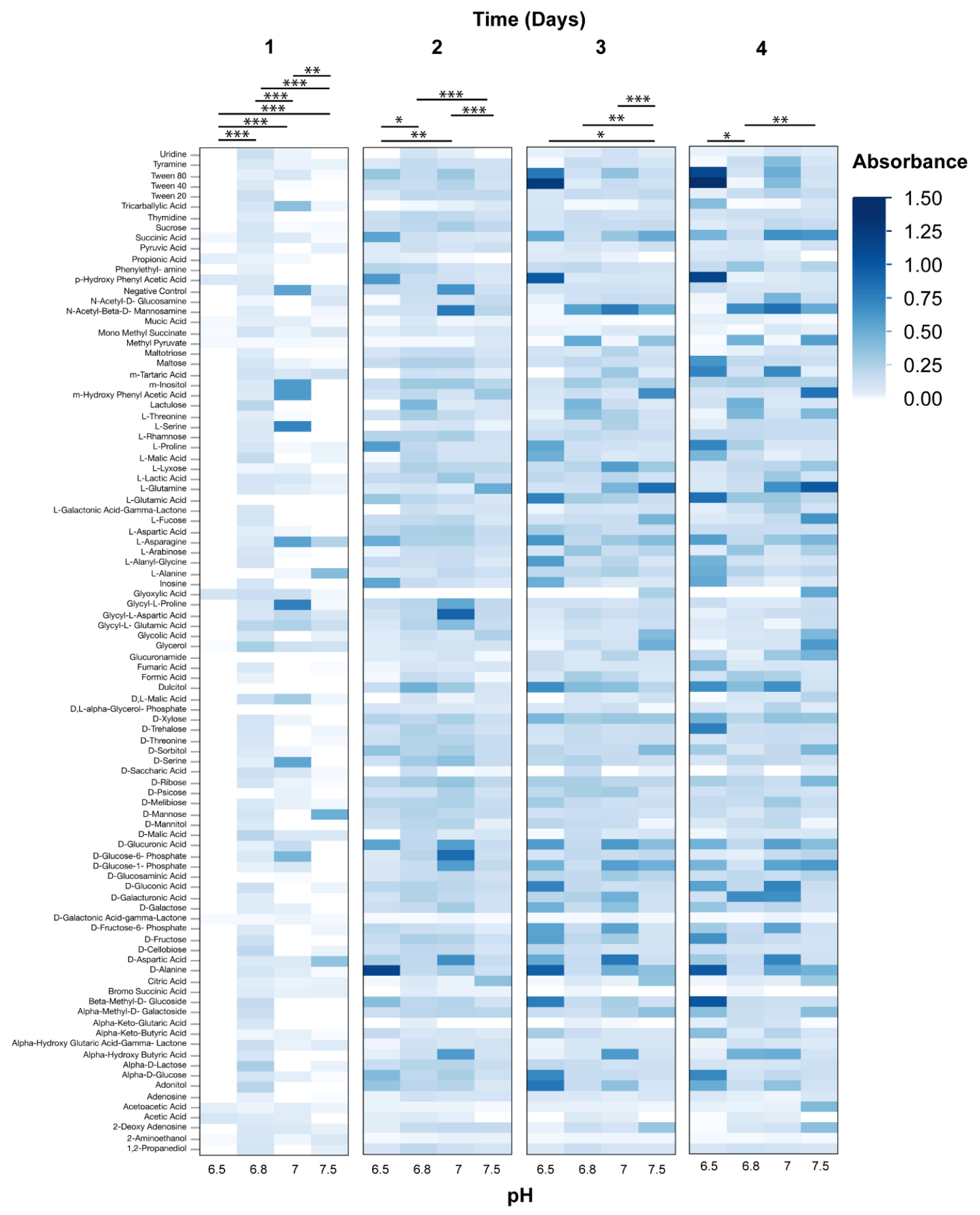

Figure 2. Heat map of PM1 phenotypic microarray data from Wolbachia isolated and maintained in Schneider's medium supplemented with $10 \%$ FBS at different $\mathrm{pH}$ levels ( $n=2$ for each treatment). All data were normalized by subtracting absorbance values of control plates containing Schneider's medium only from absorbance readings of treatment plates. Significant differences between treatments are represented by horizontal bars above each column for each timepoint (t-tests, ${ }^{*} p<0.05,{ }^{* *} p<0.005$, *** $p<0.0005$ ). 


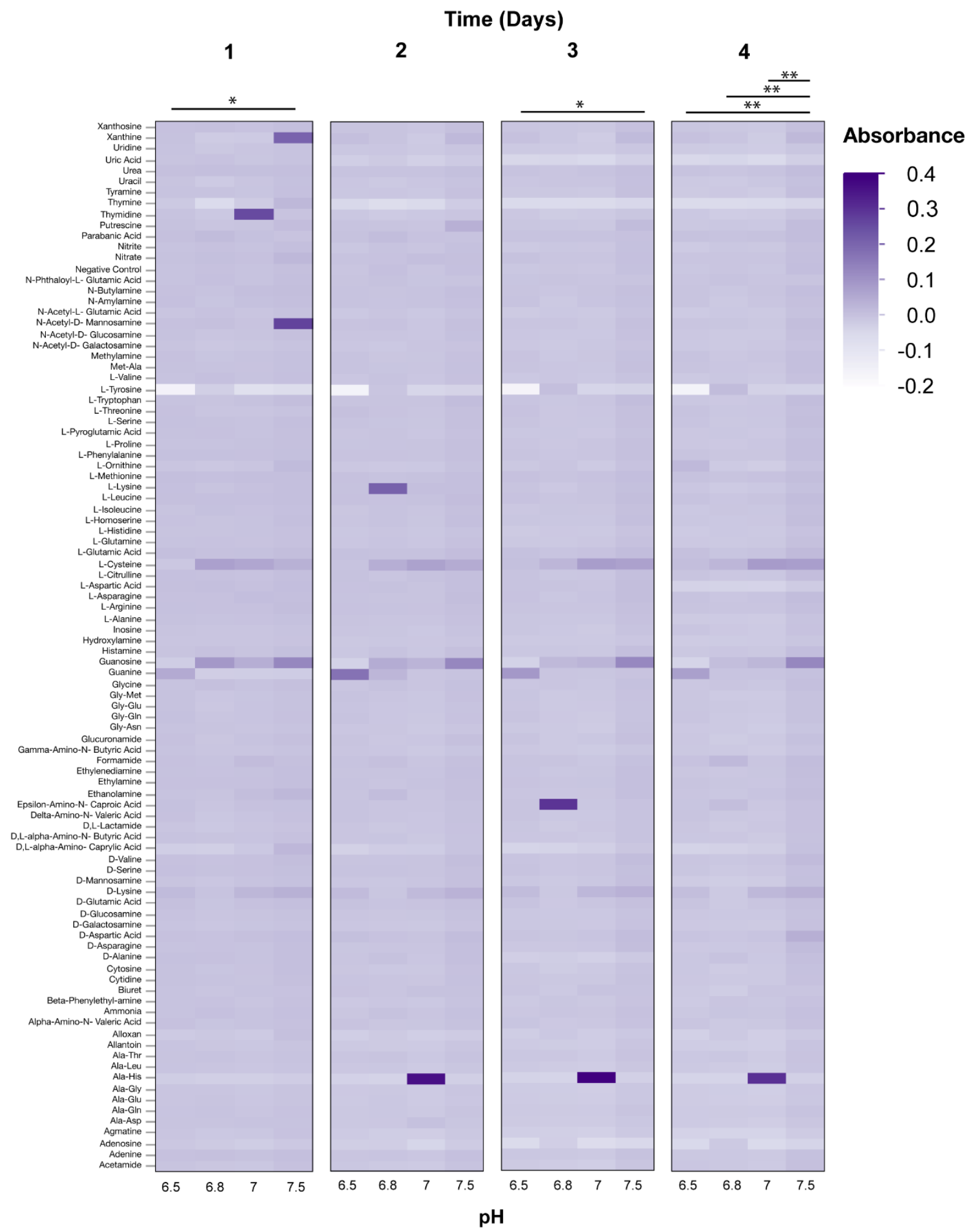

Figure 3. Heat map of PM3 phenotypic microarray data from Wolbachia isolated and maintained in Schneider's medium supplemented with $10 \%$ fetal bovine serum (FBS) at different pH levels ( $n=3$ for each treatment) All data were normalized by subtracting absorbance values of control plates containing Schneider's medium only from absorbance readings of treatment plates. Significant differences between treatments are represented by horizontal bars above each column for each timepoint (t-tests, ${ }^{*} p<0.05$, $\left.{ }^{* *} p<0.005,{ }^{* * *} p<0.0005\right)$. 


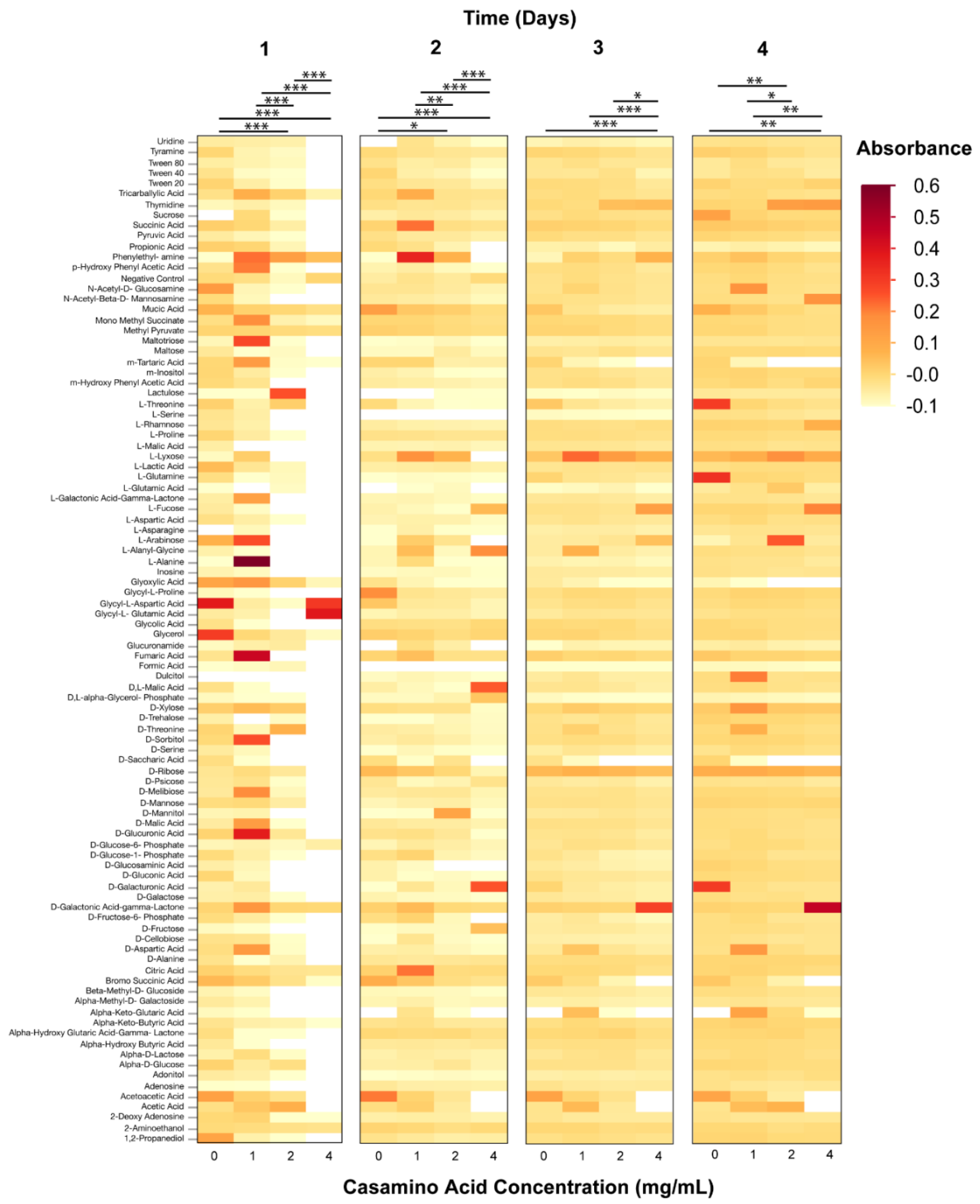

Figure 4. Heat map of PM1 phenotypic microarray data from Wolbachia isolated and maintained in Schneider's medium supplemented with 10\% FBS and different concentrations of Casamino acids ( $n=3$ for each treatment). All data were normalized by subtracting absorbance values of control plates containing Schneider's medium only from absorbance readings of treatment plates. Significant differences between treatments are represented by horizontal bars above each column for each timepoint (t-tests, $\left.{ }^{*} p<0.05,{ }^{* *} p<0.005,{ }^{* * *} p<0.0005\right)$. 


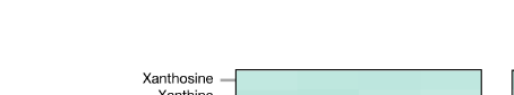

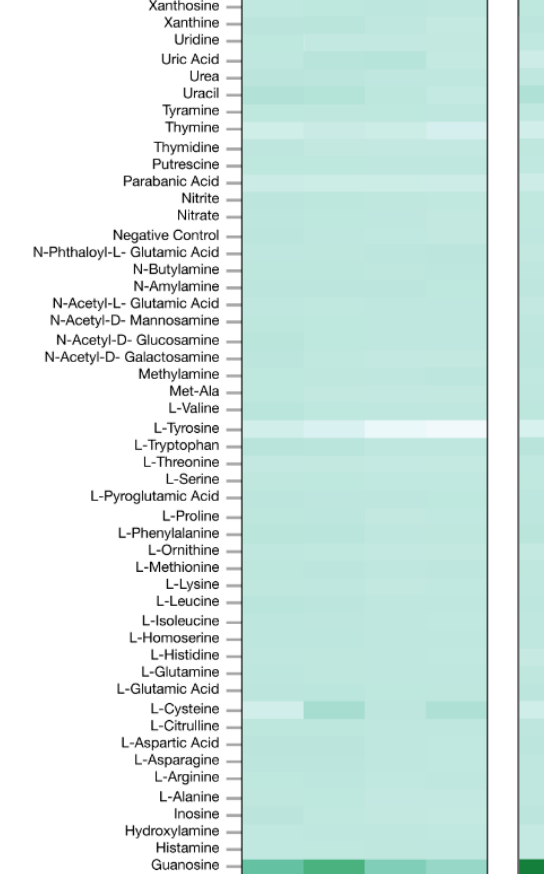

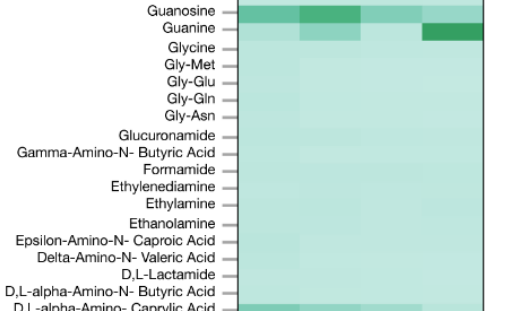

D,L-alpha-Amino- $\mathrm{N}-$ Bactamide

D,L-alpha-

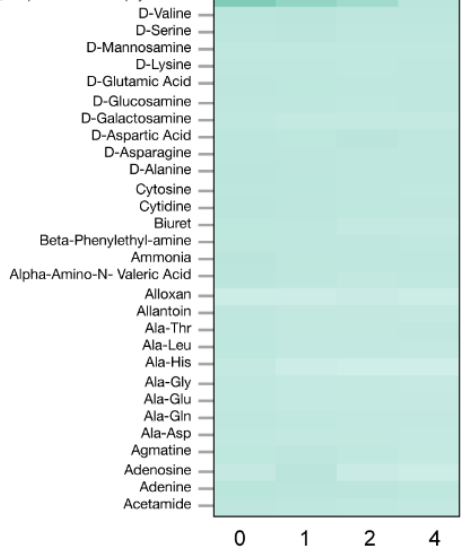

Casamino $\begin{array}{lll}1 & 2 & 4\end{array}$
2

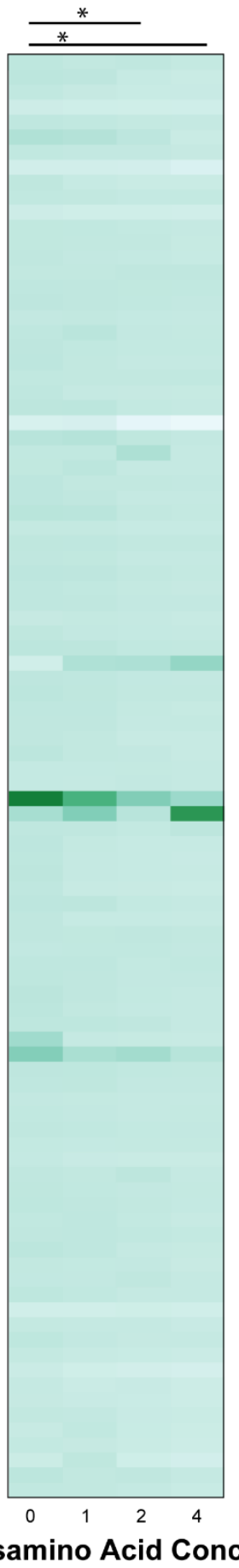

Time (Days)

3

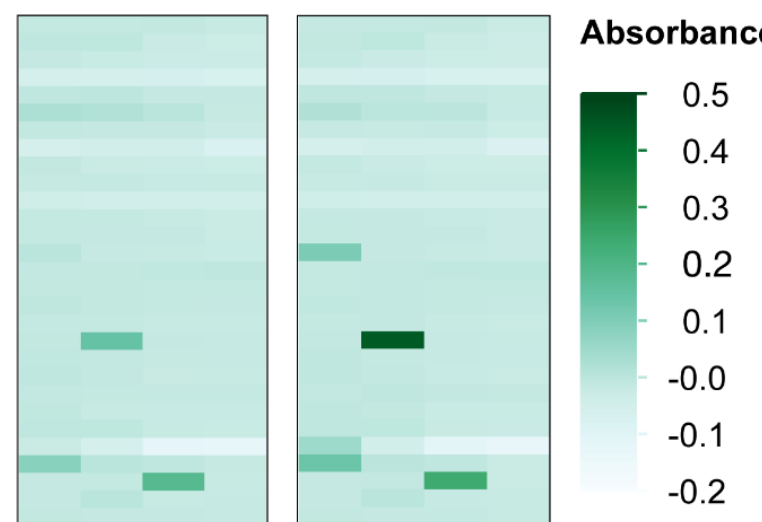

4

Figure 5. Heat map of PM3 phenotypic microarray data from Wolbachia isolated and maintained in Schneider's medium supplemented with $10 \%$ FBS and different concentrations of Casamino acids ( $n=3$ for each treatment). All data were normalized by subtracting absorbance values of control plates containing Schneider's medium only from absorbance readings of treatment plates. Significant differences between treatments are represented by horizontal bars above each column for each timepoint (t-tests, $\left.{ }^{*} p<0.05,{ }^{* *} p<0.005,{ }^{* * *} p<0.0005\right)$.

For media formulations where $\mathrm{pH}$ or casamino acid concentration was altered, substrates on PM1 and PM3 plates associated with the TCA cycle and glycolysis were oxidized (i.e., Citric 
acid, Fructose-6-phosphate, Acetic acid), suggesting that these pathways are functional in extracellular Wolbachia. The presence of membrane transporters in Wolbachia genomes for proline, aspartate/glutamate, and alanine and pathways for metabolism of amino acids suggests that Wolbachia is dependent upon purine synthesis from amino acids. The oxidation of the amino acids (L-Alanine, L-Arabinose, L-Cysteine, L-Lyxose, L-Glutamine) and the purine guanine on PM3 plates support this hypothesis.

\subsection{Quantitative Real-Time PCR}

Phenotypic microarrays suggest that a $\mathrm{pH}$ of 6.5 is optimal for an axenic medium. To investigate Wolbachia survival in an axenic medium with a $\mathrm{pH}$ of 6.5 , qPCR was used to quantify the number of Wolbachia cells post-isolation over a four-day period. A greater number of Wolbachia copies were observed in an axenic medium with a $\mathrm{pH}$ of 6.5 compared to compared to unaltered Schneider's media $+10 \%$ FBS (pH 6.8) (Kruskal-Wallis, Chi-sq $=9.0, p=0.01$ ). Results suggest an increase in the survivorship and longevity of extracellular Wolbachia in an axenic medium supplemented with a $\mathrm{pH}$ of 6.5 (Figure 6). qPCR was also used to quantify the number of Wolbachia cells over a four-day period in an axenic Wolbachia medium supplemented with $1 \mathrm{mg} / \mathrm{mL}$ of casamino acids, which showed the greatest metabolic activity in the phenotypic microarray assays. A greater number of Wolbachia copies were observed in an axenic medium supplemented with $1 \mathrm{mg} / \mathrm{mL}$ of casamino acids compared to unaltered Schneider's media $+10 \%$ FBS (Kruskal-Wallis, Chi-sq $=8.4, p=0.2$ ). Results suggest an increase in the survivorship and longevity of extracellular Wolbachia in an axenic medium supplemented with $1 \mathrm{mg} / \mathrm{mL}$ of casamino acids (Figure 6 ).
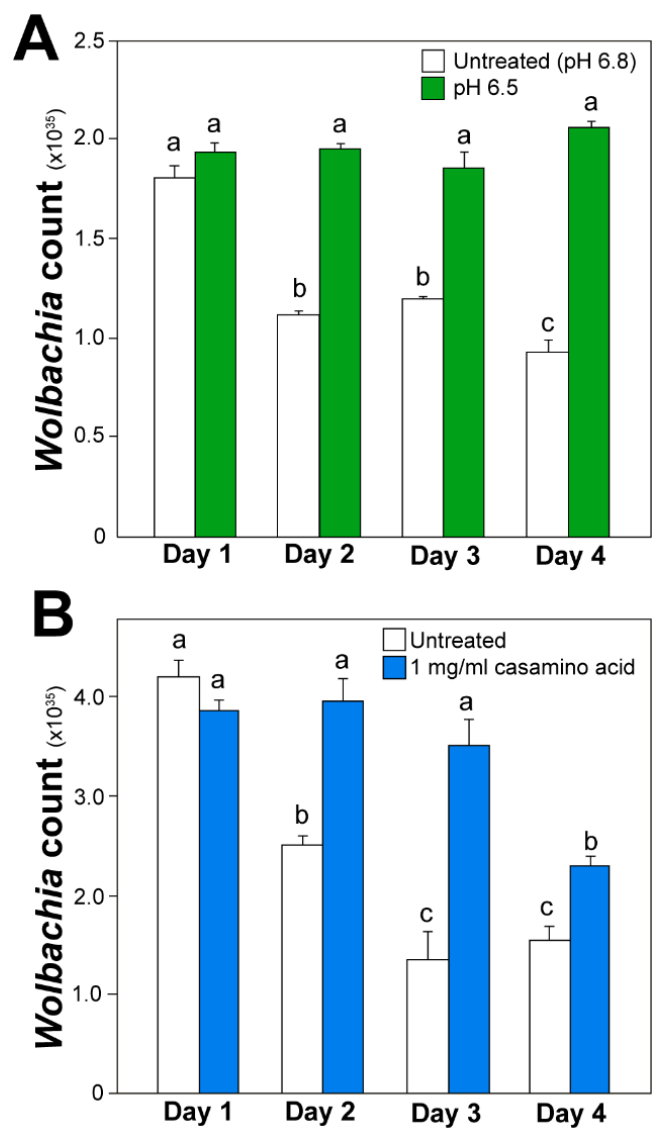

Figure 6. Extracellular Wolbachia count using quantitative polymerase chain reaction (qPCR) in (A) Schneider's medium with $10 \%$ FBS adjusted to a pH of 6.5 , and (B) Schneider's medium with $10 \%$ FBS and $1 \mathrm{mg} / \mathrm{mL}$ Casamino acids. Significant differences are indicated by different letters above each bar (Mann-Whitney, $p<0.05)$. 


\subsection{Wolbachia Cell Counts}

Baclight LIVE/DEAD ${ }^{\mathrm{TM}}$ images and cell counts were used as an additional metric to measure Wolbachia survivorship and longevity in axenic media formulations. Cell counts suggest a greater number of living Wolbachia cells in axenic media formulations with a $\mathrm{pH}$ of 6.5 and 6.8 at one, two, and three days post-Wolbachia isolation (Day 1, Kruskal-Wallis, Chi-sq = 8.94, $p=0.03$; Day 2, Kruskal-Wallis, Chi-sq = 8.95, $p=0.03$; Day 3, Kruskal-Wallis, Chi-sq = 9.46, $p=0.02$; Day 4, Kruskal-Wallis, Chi-sq = 7.76, $p=0.05$ ) (Figure 7). Cell counts also suggest a greater number of living Wolbachia cells in axenic media formulations when supplemented with $1 \mathrm{mg} / \mathrm{mL}$ of casamino acids (Day 1, Kruskal-Wallis, Chi-sq. = 8.23, $p=0.04$; Day 2, Kruskal-Wallis, Chi-sq. = 8.3, $p=0.04$; Day 3, Kruskal-Wallis, Chi-sq. = 2.3, $p=0.51$; Day 4, Kruskal-Wallis, Chi-sq. = 9.4, $p=0.02$ ) (Figure 8).

A
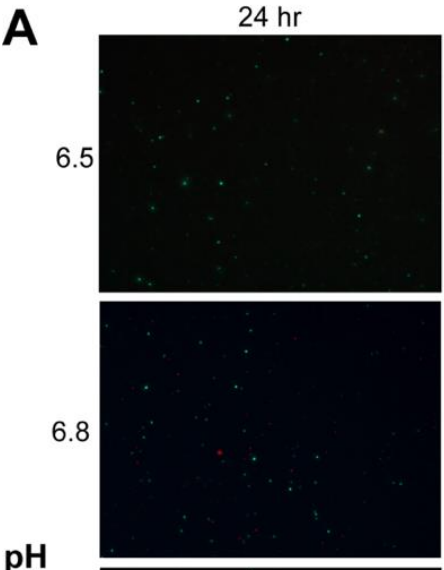

pH
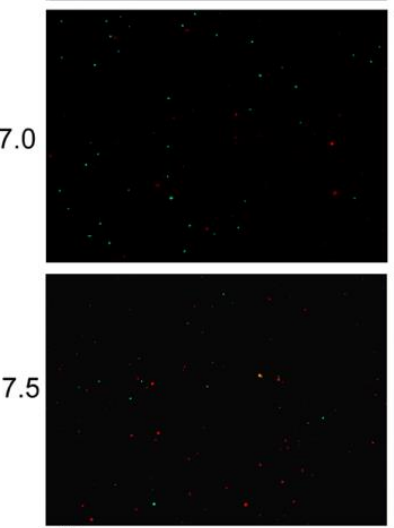

B

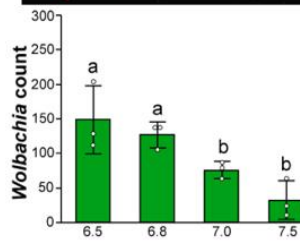

$48 \mathrm{hr}$
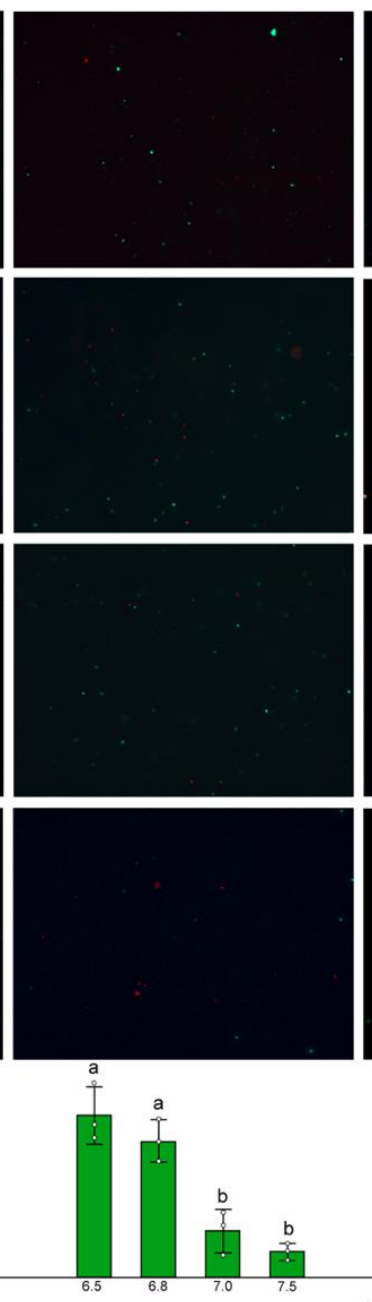

$72 \mathrm{hr}$
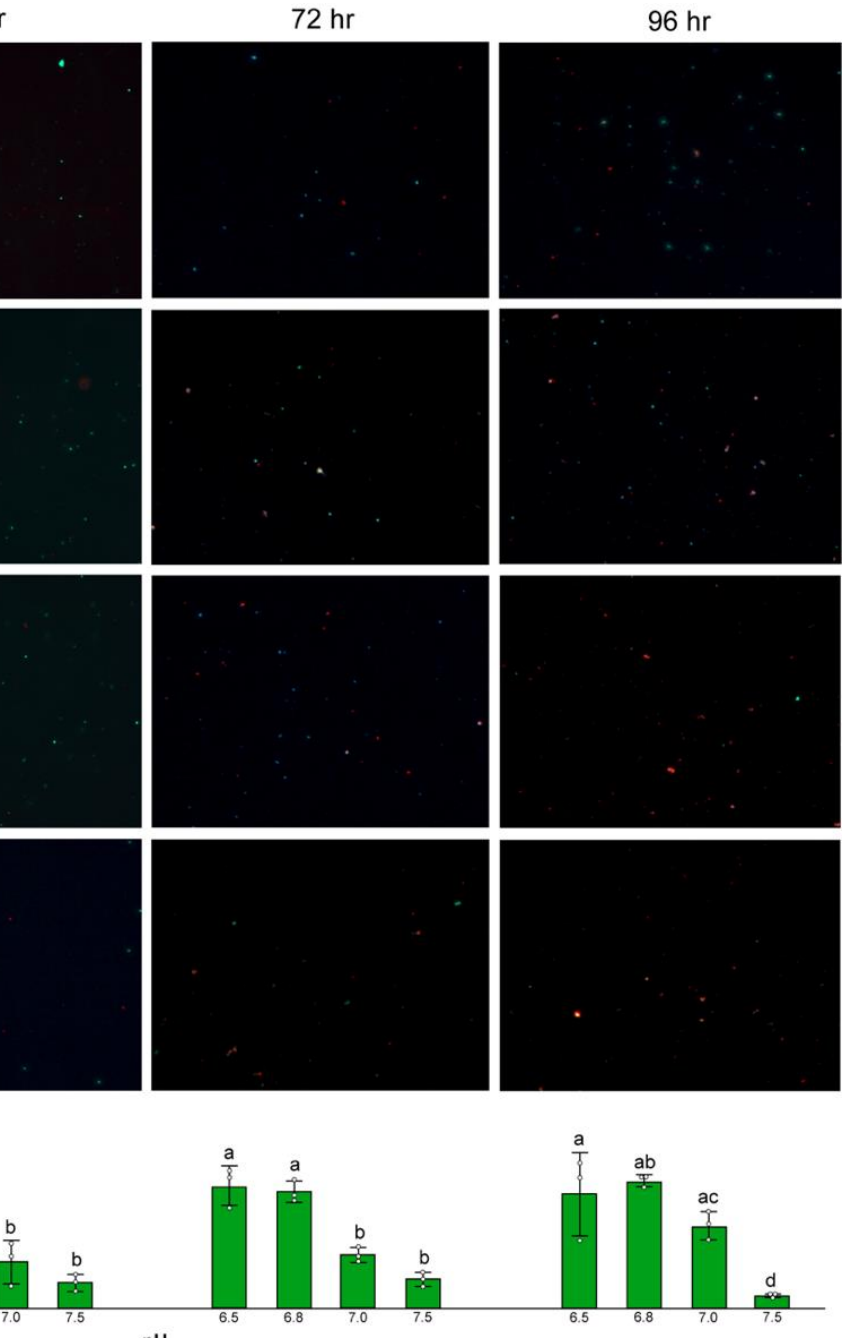

$\mathrm{pH}$

Figure 7. (A) Isolated Wolbachia stained with Baclight LIVE/DEAD ${ }^{\mathrm{TM}}$ viability assays in Schneider's medium supplemented with 10\% FBS and an adjusted $\mathrm{pH}$ of 6.5, 6.8, 7.0, and 7.5. Live and dead Wolbachia are green and red, respectively. (B) Live Wolbachia was counted using Image-J from three representative fields of view at 100x. Significant differences are indicated by different letters above each bar (Mann-Whitney, $p<0.05$ ). 
A
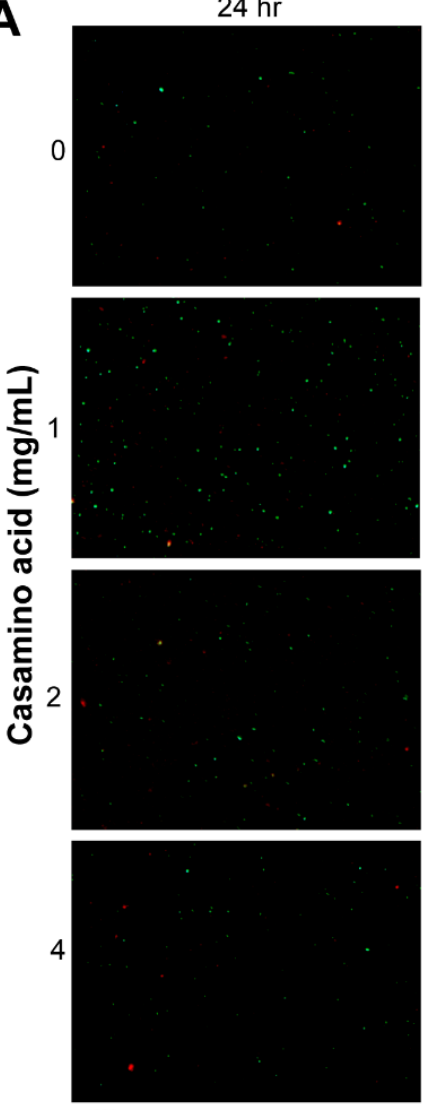

B

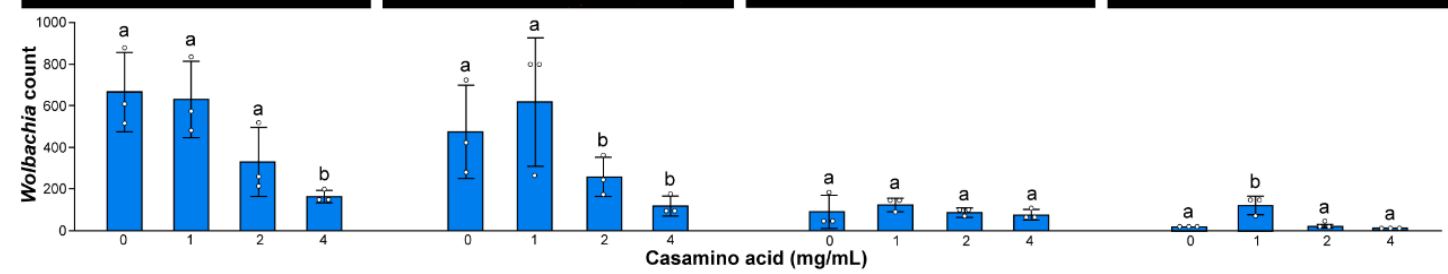

$48 \mathrm{hr}$
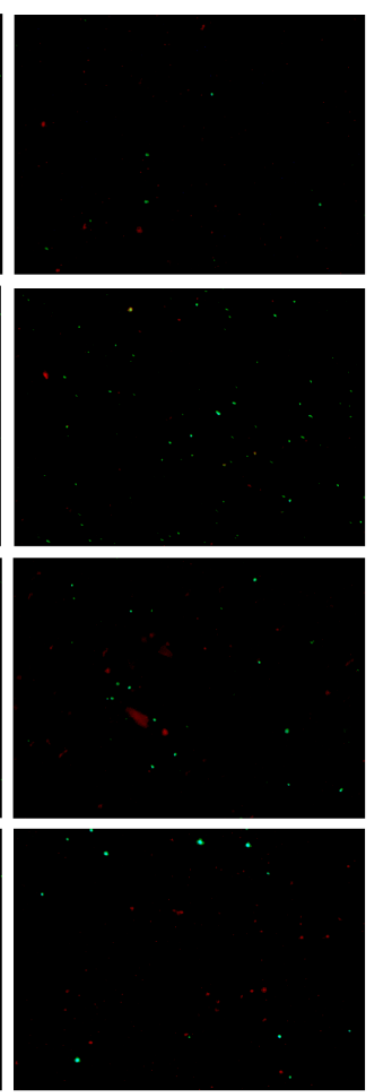

Casamino acid $(\mathrm{mg} / \mathrm{mL})$
$72 \mathrm{hr}$
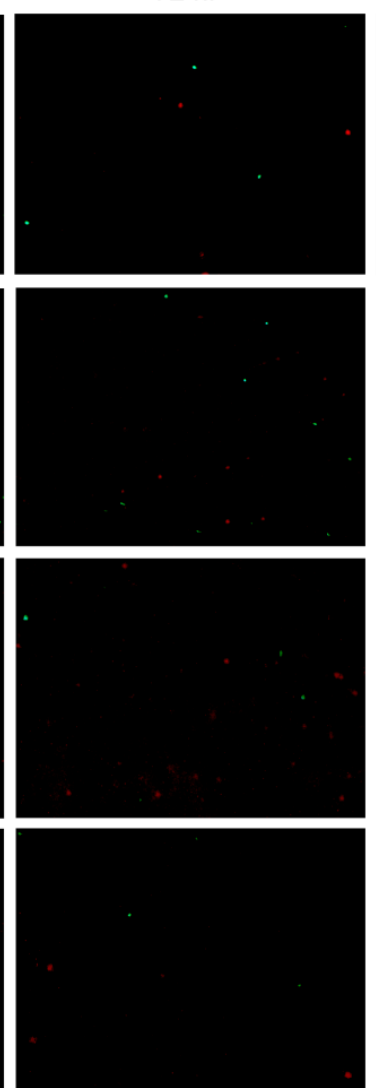
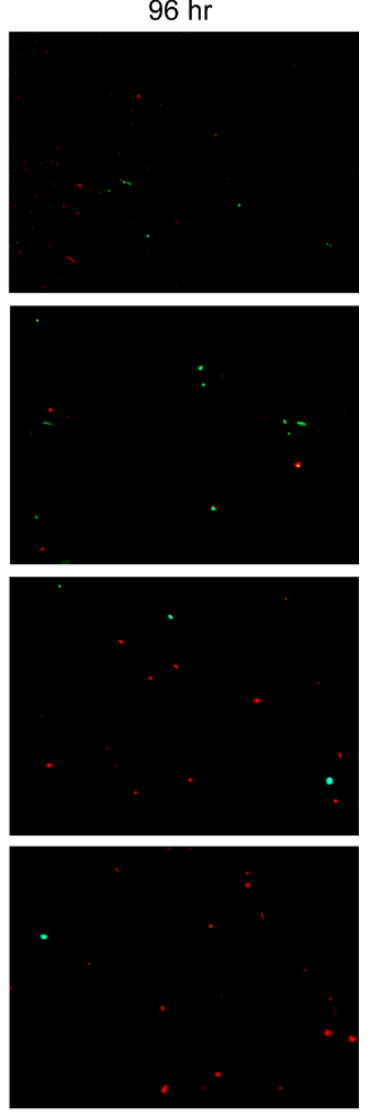

Figure 8. (A) Isolated Wolbachia stained with BacLight LIVE/DEAD ${ }^{\mathrm{TM}}$ viability assays in Schneider's medium supplemented with $10 \%$ FBS and casamino acid concentrations of $0 \mathrm{mg} / \mathrm{mL}, 1 \mathrm{mg} / \mathrm{mL}, 2 \mathrm{mg} / \mathrm{mL}$, and $4 \mathrm{mg} / \mathrm{mL}$. Live and dead Wolbachia are green and red, respectively. (B) Live Wolbachia was counted using Image-J from three representative fields of view at 100x. Significant differences are indicated by different letters above each bar (Mann-Whitney, $p<0.05$ ).

\section{Discussion}

Understanding the phenotypic response of Wolbachia outside of its host cell is an important first step in the development of an axenic Wolbachia culture and may help lead to the development of a Wolbachia-based paratransgenic interventions for insect vector borne diseases. Wolbachia-based paratransgenic approaches have remained theoretical because Wolbachia has yet to be genetically transformed inside or outside the host cell [48-50]. Separation of Wolbachia from its host cell in an axenic culture will facilitate the genetic transformation of Wolbachia by providing an axenic system to select for transformed Wolbachia cells. Selected transformed cells can reintroduced back into aposymbiotic cell lines for propagation. Furthermore, an axenic culture system will support additional studies to determine which Wolbachia genes and proteins are involved in host reproductive modifications, as well as potentially direct Wolbachia effects on pathogen disruption.

The observed metabolic activity of Wolbachia in the phenotypic microarrays provides a valuable tool to measure metabolic response to different media formulations and growth conditions outlined. The results from the phenotypic microarrays have identified several key amino acids and metabolites that require testing as supplements to axenic media formulations. Several of the compounds shown to 
have higher metabolism by Wolbachia wAlbB are a potential for precursors in the Kreb's cycle, as well as glycolysis. Also, since Wolbachia lacks any ATPase machinery and is known to rely on glycolysis to generate adenosine monophosphate (AMP), guanosine monophosphate (GMP), and xanthosine monophosphate (XMP), this suggests that Wolbachia may derive energy from amino acids [18,21]. Purine ring containing compounds like ribose, lyxose, and xylose could be potential precursors of adenosine triphosphate (ATP), guanosine triphosphate (GTP), and cyclic-AMP that may be beneficial for the Wolbachia maintenance and survival [18,51-57]. In addition, from studies on Wolbachia genomes, it is known that there are multiple proline, aspartate/glutamate, and alanine membrane transporters present in Wolbachia $[18,54,55,58,59]$. The known Wolbachia pathways of amino acid metabolism suggest that Wolbachia is dependent on purine synthesis for the amino acids. The oxidation of the above-mentioned amino acids on the PM3B plates also supports this hypothesis. Overall, this suggests a reliance of Wolbachia on host amino acids and less reliance on carbohydrates as a major source of its energy. Previous genomic studies have drawn similarities between Wolbachia and Rickettsia, where both have limited carbohydrate metabolism, lipid biosynthesis, and amino acid transport capabilities [18-21].

Changes in $\mathrm{pH}$ in an axenic medium may also play an important role in Wolbachia survival outside of its host cell. An observed increase in Wolbachia longevity and survivorship and increased metabolic activity on phenotypic microarrays suggests that an axenic medium consisting of a $\mathrm{pH}$ of 6.5-6.8 may be most appropriate for Wolbachia survival outside of its host cell. The observed increase in Wolbachia longevity and survivorship, and increased metabolic activity on phenotypic microarrays, suggest a $1 \mathrm{mg} / \mathrm{mL}$ of casamino acids may also be an important component in an axenic medium formulation by providing amino acid precursors for energy production in addition to the components and amino acids in Schneider's media (Table S1). Collectively, the data suggests that a medium consisting of Schneider's insect media, 10\%FBS, $1 \mathrm{mg} / \mathrm{mL}$ Casamino acids, and a pH of 6.5-6.8 is the best suited for maintaining viable extracellular up to four days. Additional experiments with the aforementioned medium formulation are required to determine if the medium formulation identified in this work will sustain Wolbachia longer than previous reports of seven days [13].

The identified medium conditions, as well as other metabolites identified on phenotypic microarrays, suggest the potential to develop an axenic medium to support the survivorship and potential replication of Wolbachia outside of its host cell. Whereas replication of Wolbachia in an axenic medium would be a significant research achievement and would open multiple avenues for future research, this may not be possible due to the intracellular nature of Wolbachia and reliance of Wolbachia on its host cell for its machinery and nutrients. However, if Wolbachia could be maintained outside of the host cell for a period of time and remain viable, Wolbachia could be transformed, and the transformed cells could be selected and reintroduced back into a novel insect or host cell line. Future work will focus on increasing the longevity and survivorship outside of the host cell with the ultimate goal of Wolbachia replication in an axenic medium. The observed results from this study also provide insight into the development of methodology to culture intracellular pathogens, such as closely related Rickettsia species, as well as Chlamydiae species, which result in Rocky Mountain spotted fever (RMSF) and chlamydial infections, respectively.

\section{Conclusions}

In conclusion, we demonstrated that Wolbachia can be isolated and its metabolic activity can be measured using phenotypic microarrays. In addition, we edemonstrated that amino acid supplementation, as well as adjusting $\mathrm{pH}$ similar to the internal environment of an insect cell, impacts the phenotypic response of Wolbachia and increases the survivorship of Wolbachia outside of its host cell. Future work will incorporate identified metabolites from phenotypic microarrays with different media formulations in an attempt to develop an axenic medium that will extend the survivorship and longevity of Wolbachia and/or examine for Wolbachia replication outside of the host cell. 
Supplementary Materials: The following are available online at http://www.mdpi.com/2076-2607/8/7/1060/s1, Table S1: Schneider's media formulation (Sigma-S0146), Table S2: Primer sequences used to assay Wolbachia and other potential bacterial infections in cell cultures and Wolbachia extractions, Table S3: Wolbachia isolate bacterial infections status determined by PCR.

Author Contributions: Conceptualization, C.L.B.; methodology, C.L.B., A.G., and A.M.K.; software, C.L.B.; validation, A.M.K., A.G.; formal analysis, C.L.B., A.G., A.M.K.; investigation, A.G. and A.M.K.; data curation, C.L.B. and A.K.; writing-original draft preparation, C.L.B., A.G., and A.M.K.; writing-review and editing, C.L.B and A.M.K.; visualization, C.L.B. and A.M.K.; supervision, C.L.B.; project administration, C.L.B. All authors have read and agreed to the published version of the manuscript.

Funding: This research was funded by start-up funds from Texas Tech University.

Acknowledgments: We thank Catherine Wakeman (Texas Tech University) for allowing us to use the Biotek Synergy H1 Microplate Reader (Winooski, VT). We thank Zhiyong Xi (Michigan State University) for providing the Aa23 cell line.

Conflicts of Interest: The authors declare no conflict of interest.

\section{References}

1. Werren, J.H.; Windsor, D.M. Wolbachia infection frequencies in insects: Evidence of a global equilibrium? Proc. Biol. Sci. 2000, 267, 1277-1285. [CrossRef]

2. Hilgenboecker, K.; Hammerstein, P.; Schlattmann, P.; Telschow, A.; Werren, J.H. How many species are infected with Wolbachia?-A statistical analysis of current data. Fems. Microbiol. Lett. 2008, 281, 215-220. [CrossRef]

3. Werren, J.H.; Baldo, L.; Clark, M.E. Wolbachia: Master manipulators of invertebrate biology. Nat. Rev. Microbiol. 2008, 6, 741-751. [CrossRef]

4. Moreira, L.A.; Iturbe-Ormaetxe, I.; Jeffery, J.A.; Lu, G.; Pyke, A.T.; Hedges, L.M.; Rocha, B.C.; Hall-Mendelin, S.; Day, A.; Riegler, M.; et al. A Wolbachia symbiont in Aedes aegypti limits infection with dengue, Chikungunya, and Plasmodium. Cell 2009, 139, 1268-1278. [CrossRef]

5. Hurk, v.d.A.F.; Hall-Mendelin, S.; Pyke, A.T.; Frentiu, F.D.; McElroy, K.; Day, A.; Higgs, S.; O’Neill, S.L. Impact of Wolbachia on infection with chikungunya and yellow fever viruses in the mosquito vector Aedes aegypti. PLoS Negl. Trop. Dis. 2012, 6, e1892.

6. Caragata, E.P.; Dutra, H.L.C.; Moreira, L.A. Inhibition of Zika virus by Wolbachia in Aedes aegypti. Microb. Cell 2016, 3, 293-295. [CrossRef]

7. Tan, C.H.; Wong, P.J.; Li, M.I.; Yang, H.T.; Ng, L.C.; O’Neill, S.L. wMel limits zika and chikungunya virus infection in a Singapore Wolbachia-introgressed Ae. aegypti strain, wMel-Sg. PLoS. Negl. Trop. Dis. 2017, 11, e0005496. [CrossRef]

8. Flores, H.A.; O'Neill, S.L. Controlling vector-borne diseases by releasing modified mosquitoes. Nat. Rev. Microbiol. 2018, 16, 508-518. [CrossRef]

9. Mains, J.W.; Brelsfoard, C.L.; Rose, R.I.; Dobson, S.L. Femal adult Aedes albopictus suppression by Wolbachia-infected male mosquitoes. Sci. Rep. 2016, 6, 33846. [CrossRef]

10. Aultman, K.S.; Beaty, B.J.; Walker, E.D. Genetically manipulated vectors of human disease: A practical overview. Trends Para. 2001, 17, 507-509. [CrossRef]

11. Aksoy, S.; Weiss, B.; Attardo, G. Paratransgenesis applied for control of tsetse transmitted sleeping sickness. In Transgenesis and the Management of Vector-Borne Disease; Springer: New York, NY, USA, 2008; Volume 627, pp. 35-48.

12. Bourtzis, K. Wolbachia-based technologies for insect pest population control. Adv. Exp. Med. Biol. 2008, 627, 104-113. [PubMed]

13. Rasgon, J.L.; Gamston, C.E.; Xiaoxia, R. Survival of Wolbachia pipientis in cell-free medium. Appl. Env. Micro. 2006, 72, 6934-6937. [CrossRef] [PubMed]

14. Hughes, G.L.; Koga, R.; Xue, P.; Fukatsu, T.; Rasgon, J.L. Wolbachia infections are virulent and inhibit the human malaria parasite Plasmodium falciparum in Anopheles gambiae. PLoS Pathog. 2011, 7, e1002043. [CrossRef] [PubMed]

15. Dobson, S.L.; Bourtzis, K.; Braig, H.R.; Jones, B.F.; Zhou, W.; Rousset, F.; O’Neill, S.L. Wolbachia infections are distributed throughout insect somatic and germ line tissues. Insect Biochem. Mol. Biol. 1999, 29, 153-160. [CrossRef] 
16. Frydman, H.M.; Li, J.M.; Robson, D.N.; Wieschaus, E. Somatic stem cell niche tropism in Wolbachia. Nature 2006, 441, 509-512. [CrossRef]

17. Gamston, C.; Rasgon, J. Maintaining Wolbachia in cell-free medium. J. Vis. Exp. 2007, 233. [CrossRef]

18. Wu, M.; Sun, L.V.; Vamathevan, J.; Riegler, M.; Deboy, R.; Brownlie, J.C.; McGraw, E.A.; Martin, W.; Esser, C.; Ahmadinejad, N.; et al. Phylogenomics of the reproductive parasite Wolbachia pipientis wMel: A streamlined genome overrun by mobile genetic elements. PLoS Bio. 2004, 2, E69. [CrossRef]

19. Brownlie, J.C.; O’Neill, S.L. Wolbachia genomes: Insights into an intracellular lifestyle. Curr. Biol. 2005, 15, R507-R509. [CrossRef]

20. Klasson, L.; Westberg, J.; Sapountzis, P.; Naslund, K.; Lutnaes, Y.; Darby, A.C.; Veneti, Z.; Chen, L.; Braig, H.R.; Garrett, R.; et al. The mosaic genome structure of the Wolbachia wRi strain infecting Drosophila simulans. Proc. Natl. Acad. Sci. USA 2009, 106, 5725-5730. [CrossRef]

21. Maren Ellegaard, K.; Klasson, L.; Naslund, K.; Bourtzis, K.; Anderson, S. Comparative genomics of Wolbachia and the bacterial species concept. PLoS Genet. 2013, 9, e1003381. [CrossRef]

22. White, P.M.; Serbus, L.R.; Debec, A.; Codina, A.; Bray, W.; Guichet, A.; Lokey, R.S.; Sullivan, W. Reliance of Wolbachia on High Rates of Host Proteolysis Revealed by a Genome-Wide RNAi Screen of Drosophila Cells. Genetics 2017, 205, 1473-1488. [CrossRef] [PubMed]

23. Foster, J.; Ganatra, M.; Kamal, I.; Ware, J.; Makarova, K.; Ivanova, N.; Bhattacharyya, A.; Kapatral, V.; Kumar, S.; Posfai, J.; et al. The Wolbachia genome of Brugia malayi: Endosymbiont evolution within a human pathogenic nematode. PLoS Biol. 2005, 3, e121. [CrossRef] [PubMed]

24. Driscoll, T.P.; Verhoeve, V.I.; Guillotte, M.L.; Lehman, S.S.; Rennoll, S.A.; Beier-Sexton, M.; Rahman, M.S.; Azad, A.F.; Gillespie, J.J. Wholly Rickettsia! Reconstructed Metabolic Profile of the Quintessential Bacterial Parasite of Eukaryotic Cells. MBio 2017, 8, e00859-17. [CrossRef] [PubMed]

25. Marmion, B.P.; Storm, P.A.; Ayres, J.G.; Semendric, L.; Mathews, L.; Winslow, W.; Turra, M.; Harris, R.J. Long-term persistence of Coxiella burnetii after acute primary $Q$ fever. QJM 2005, 98, 7-20. [CrossRef]

26. Vlak, J.M.; de Gooijer, C.D.; Tramper, J.; Miltenburger, H.G. Insect Cell Cultures: Fundamental and Applied Aspects; Springer: Dordrecht, The Netherlands, 1996.

27. Medina, M.; Lopez-Rivas, A.; Zuidema, D.; Belsham, G.J.; Domingo, E.; Vlak, J.M. Strong buffering capacity of insect cells. Implications for the baculovirus expression system. Cytotechnology 1995, 17, 21-26. [CrossRef]

28. Beare, P.A.; Jeffrey, B.M.; Long, C.M.; Martens, C.M.; Heinzen, R.A. Genetic mechanisms of Coxiella burnetii lipopolysaccharide phase variation. PLoS Pathog. 2018, 14, e1006922. [CrossRef]

29. Beare, P.A.; Larson, C.L.; Gilk, S.D.; Heinzen, R.A. Two systems for targeted gene deletion in Coxiella burnetii. Appl. Env. Microbiol. 2012, 78, 4580-4589. [CrossRef]

30. Clay, K.A.; Hartley, M.G.; Russell, P.; Norville, I.H. Use of axenic media to determine antibiotic efficacy against Coxiella burnetii. Int. J. Antimicrob. Agents 2018, 51, 806-808. [CrossRef]

31. Omsland, A.; Cockrell, D.C.; Fischer, E.R.; Heinzen, R.A. Sustained axenic metabolic activity by the obligate intracellular bacterium Coxiella burnetii. J. Bacteriol. 2008, 190, 3203-3212. [CrossRef]

32. Sanchez, S.E.; Vallejo-Esquerra, E.; Omsland, A. Use of Axenic Culture Tools to Study Coxiella burnetii. Curr. Protoc. Microbiol. 2018, 50, e52. [CrossRef]

33. Sandoz, K.M.; Popham, D.L.; Beare, P.A.; Sturdevant, D.E.; Hansen, B.; Nair, V.; Heinzen, R.A. Transcriptional Profiling of Coxiella burnetii Reveals Extensive Cell Wall Remodeling in the Small Cell Variant Developmental Form. PLoS ONE 2016, 11, e0149957. [CrossRef] [PubMed]

34. Pontes, M.H.; Dale, C. Culture and manipulation of insect facultative symbionts. Trends Microbiol. 2006, 14, 406-412. [CrossRef]

35. Omsland, A.; Cockrell, D.C.; Howe, D.; Fischer, E.R.; Virtaneva, K.; Sturdevant, D.E.; Porcella, S.F.; Heinzen, R.A. Host cell-free growth of the $\mathrm{Q}$ fever bacterium Coxiella burnetii. Proc. Natl. Acad. Sci. USA 2009, 106, 4430-4434. [CrossRef]

36. Omsland, A.; Hackstadt, T.; Heinzen, R.A. Bringing culture to the uncultured: Coxiella burnetii and lessons for obligate intracellular bacterial pathogens. PLoS Pathog. 2013, 9, e1003540. [CrossRef] [PubMed]

37. Brandt, J.W.; Chevignon, G.; Oliver, K.M.; Strand, M.R. Culture of an aphid heriTable Symbiont demonstrates its direct role in defence against parasitoids. Proc. Biol. Sci. 2017, 284, 20171925. [CrossRef] [PubMed]

38. Matthew, C.Z.; Darby, A.C.; Young, S.A.; Hume, L.H.; Welburn, S.C. The rapid isolation and growth dynamics of the tsetse symbiont Sodalis glossinidius. Fems. Microbiol. Lett. 2005, 248, 69-74. [CrossRef] [PubMed] 
39. Masson, F.; Calderon Copete, S.; Schupfer, F.; Garcia-Arraez, G.; Lemaitre, B. In Vitro Culture of the Insect Endosymbiont Spiroplasma poulsonii Highlights Bacterial Genes Involved in Host-Symbiont Interaction. MBio 2018, 9, e00024-18. [CrossRef]

40. O'Neill, S.L.; Pettigrew, M.M.; Sinkins, S.P.; Braig, H.R.; Andreadis, T.G.; Tesh, R.B. In vitro cultivation of Wolbachia pipientis in an Aedes albopictus cell line. Insect Mol. Biol. 1997, 6, 33-39. [CrossRef]

41. McGraw, E.A.; Merritt, D.J.; Droller, J.N.; O'Neill, S.L. Wolbachia-mediated sperm modification is dependent on the host genotype in Drosophila. Proc. Biol. Sci. 2001, 268, 2565-2570. [CrossRef]

42. Minard, G.; Tran, F.H.; Raharimalala, F.N.; Hellard, E.; Ravelonandro, P.; Mavingui, P.; Valiente Moro, C. Prevalence, genomic and metabolic profiles of Acinetobacter and Asaia associated with field-caught Aedes albopictus from Madagascar. Fems. Microbiol. Ecol. 2013, 83, 63-73. [CrossRef]

43. Mühling, M.; Woolven-Allen, J.; Murrell, J.C.; Joint, I. Improved group-specific PCR primers for denaturing gradient gel electrophoresis analysis of the genetic diversity of complex microbial communities. Isme. J. 2008, 2, 379. [CrossRef]

44. Schneider, C.A.; Rasband, W.S.; Eliceiri, K.W. NIH Image to ImageJ: 25 years of image analysis. Nat. Methods 2012, 9, 671-675. [CrossRef] [PubMed]

45. Voronin, D.; Tran-Van, V.; Potier, P.; Mavingui, P. Transinfection and growth discrepancy of Drosophila Wolbachia strain $w \mathrm{Mel}$ in cell lines of the mosquito Aedes albopictus. J. Appl. Microbiol. 2010, 108, 2133-2141. [PubMed]

46. Mackie, A.M.; Hassan, K.A.; Paulsen, I.T.; Tetu, S.G. Biolog Phenotype Microarrays for phenotypic characterization of microbial cells. Methods Mol. Biol. 2014, 1096, 123-130. [PubMed]

47. Mee, P.T.; Weeks, A.R.; Walker, P.J.; Hoffmann, A.A.; Duchemin, J.-B. Detection of Low-Level Cardinium and Wolbachia Infections in Culicoides. Appl. Env. Microbiol. 2015, 81, 6177-6188. [CrossRef] [PubMed]

48. Turelli, M.; Hoffman, A.A. Microbe-induced cytoplasmic incompatibility as a mechanism for introducing transgenes into arthropod populations. Insect Mol. Biol. 1999, 8, 243-255. [CrossRef]

49. Coutinho-Abreu, I.V.; Zhu, K.Y.; Ramalho-Ortigao, M. Transgenesis and paratransgenesis to control insect-borne diseases: Current status and future challenges. Parasitol. Int. 2010, 59, 1-8. [CrossRef]

50. Kriesner, P.; Hoffmann, A.A.; Lee, S.F.; Turelli, M.; Weeks, A.R. Rapid sequential spread of two Wolbachia variants in Drosophila simulans. PLoS Pathog. 2013, 9, e1003607. [CrossRef]

51. Berg, I.A.; Kockelkorn, D.; Buckel, W.; Fuchs, G. A 3-hydroxypropionate/4-hydroxybutyrate autotrophic carbon dioxide assimilation pathway in Archaea. Science 2007, 318, 1782-1786. [CrossRef]

52. Cho, E.A.; Lee, D.W.; Cha, Y.H.; Lee, S.J.; Jung, H.C.; Pan, J.G.; Pyun, Y.R. Characterization of a novel D-lyxose isomerase from Cohnella laevoribosii RI-39 sp. nov. J. Bacteriol. 2007, 189, 1655-1663. [CrossRef]

53. Darby, A.C.; Armstrong, S.D.; Bah, G.S.; Kaur, G.; Hughes, M.A.; Kay, S.M.; Koldkjaer, P.; Rainbow, L.; Radford, A.D.; Blaxter, M.L.; et al. Analysis of gene expression from the Wolbachia genome of a filarial nematode supports both metabolic and defensive roles within the symbiosis. Genome Res. 2012, 22, 2467-2477. [CrossRef]

54. Grote, A.; Voronin, D.; Ding, T.; Twaddle, A.; Unnasch, T.R.; Lustigman, S.; Ghedin, E. Defining Brugia malayi and Wolbachia symbiosis by stage-specific dual RNA-seq. PLoS Negl. Trop. Dis. 2017, 11, e0005357. [CrossRef] [PubMed]

55. Moreira, L.A.; Ye, Y.H.; Turner, K.; Eyles, D.W.; McGraw, E.A.; O’Neill, S.L. The wMelPop strain of Wolbachia interferes with dopamine levels in Aedes aegypti. Parasit. Vectors 2011, 4, 28. [CrossRef] [PubMed]

56. Rohrscheib, C.E.; Bondy, E.; Josh, P.; Riegler, M.; Eyles, D.; van Swinderen, B.; Weible, M.W.; Brownlie, J.C. Wolbachia Influences the Production of Octopamine and Affects Drosophila Male Aggression. Appl. Env. Microbiol. 2015, 81, 4573-4580.

57. Valentine, R.C.; Bojanowski, R.; Gaudy, E.; Wolfe, R.S. Mechanism of the allantoin fermentation. J. Biol. Chem. $1962,237,2271-2277$. 
58. Beckmann, J.F.; Ronau, J.A.; Hochstrasser, M. A Wolbachia deubiquitylating enzyme induces cytoplasmic incompatibility. Nat. Microbiol. 2017, 2, 17007. [CrossRef]

59. Zhang, G.; Hussain, M.; Asgari, S. Regulation of arginine methyltransferase 3 by a Wolbachia-induced microRNA in Aedes aegypti and its effect on Wolbachia and dengue virus replication. Insect Biochem. Mol. Biol. 2014, 53, 81-88. [CrossRef] 